\title{
A special case of synovial chondromatosis in the temporoman- dibular joint
}

\author{
Hyun-Suk Kim ${ }^{1}$, Pil-Young Yun ${ }^{1}$, and Young-Kyun Kim ${ }^{1,2 *}$ \\ ${ }^{1}$ Department of Oral and Maxillofacial Surgery, Seoul National University Bundang Hospital, Seongnam 13620, Repulic \\ of Korea \\ ${ }^{2}$ Dental Research Institute, School of Dentistry, Seoul National University, Seoul 03129, Repulic of Korea
}

(Received Jan. 11, 2017; Revised version received Feb. 24, 2017; Accepted Mar. 3, 2017)

\begin{abstract}
Synovial chondromatosis (SC) of the temporomandibular joint (TMJ) is a rare disorder that affects the synovial membrane of joints. Its nonspecific manifestations, such as orofacial pain or joint sounds upon mouth opening, are difficult to distinguish from the symptoms of conventional temporomandibular joint disorders (TMD). This paper reports a 22-year-old female having primary complaint of pain and mouth opening limitations in the left TMJ. She was referred from local clinics, after two years of treatments for TMD had failed. Computed tomography revealed conglomerated calcified bodies in the superior joint space of the left TMJ. Open surgery was performed successfully under general anesthesia, and a total of 124 calcified masses were removed from the joint. The histopathological findings confirmed synovial chondromatosis. Postoperatively, improvement was observed in the patient's symptoms.
\end{abstract}

KEY WORDS: Synovial chondromatosis, Temporomandibular joint disorder

\section{Introduction}

First described by Axhausen in 1933, synovial chondromatosis (SC) of the temporomandibular joint (TMJ) is a rare neoplastic condition and its nonspecific manifestations, such as orofacial pain or joint sounds upon mouth opening, are difficult to distinguish from the symptoms of generically referred temporomandibular joint disorders (TMD), which are relatively more common $[1,2]$. Because the distinctions between the two diseases are difficult and their initial symptoms most often resolve spontaneously, many patients may not be treated properly until a differential diagnosis is carried out based on careful radiographic examinations [3]. Therefore it is important to suspect and establish a correct diagnosis to prevent any delay in appropriate treat-

*Corresponding author: Young-Kyun Kim

Department of Oral and Maxillofacial Surgery, Section of Dentistry, Seoul National University Bundang Hospital, 82 Gumi-ro 173 beon-gil, Bundang-gu, Seongnam 13620, Repulic of Korea

Tel.: +82-31-787-7541, Fax: +82-31-787-4068

E-mail:kyk0505@snubh.org,kyk0505@daum.net ment [4]. This report presents a case of 124 cartilaginous nodules removed from the superior joint of the left TMJ in a patient who was initially misdiagnosed with TMD and treated for two years in local clinics without improvement.

\section{Case Report}

A 22-year-old Korean female with the complaint of chronic pain and mouth opening limitations in the left TMJ was referred to the Seoul National University Bundang Hospital - Department of Oral and Maxillofacial Surgery on July 2015 by a local dental clinic after two years of conventional TMD treatments had failed. The patient presented with persistent, occasional bilateral TMJ locking, left TMJ crepitation, and chronic pre-auricular pain upon mouth opening. The patient did not identify any traumatic history.

The initial diagnostic panoramic and TM-panoramic radiographs revealed multiple bony masses and an irregular condyle surface on the left TMJ (Fig. 1A). Subsequent cone-beam computed tomography (CBCT) of the 
Hyun-Suk Kim et al.
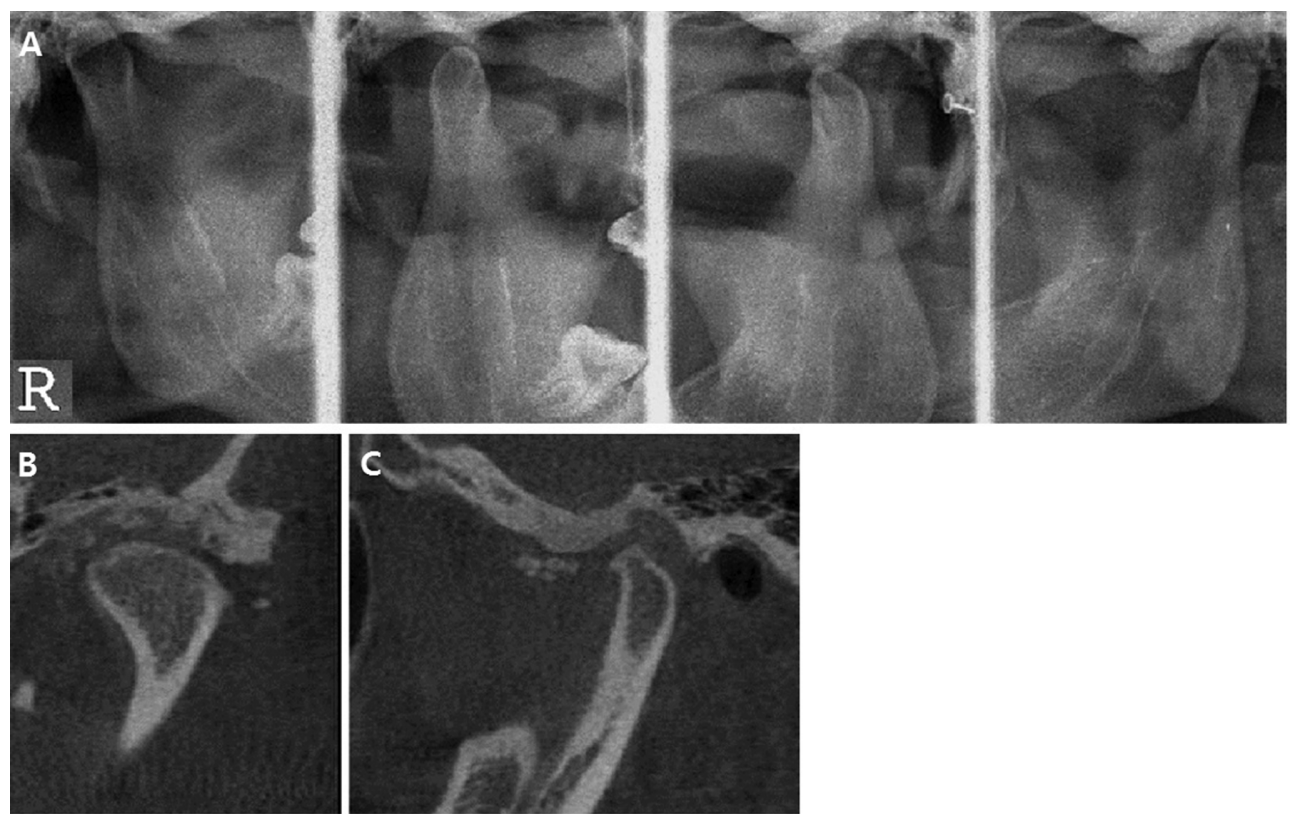

Fig. 1. TM-panoramic view (A) and CBCT (B and C) findings of the left TMJ. Panel A shows numerous conglomerated radiopaque masses on the left TMJ anterior portion. Panel B (coronal view) and C (sagittal view) show 3-dimensional size and location of the calcified masses more definitely.
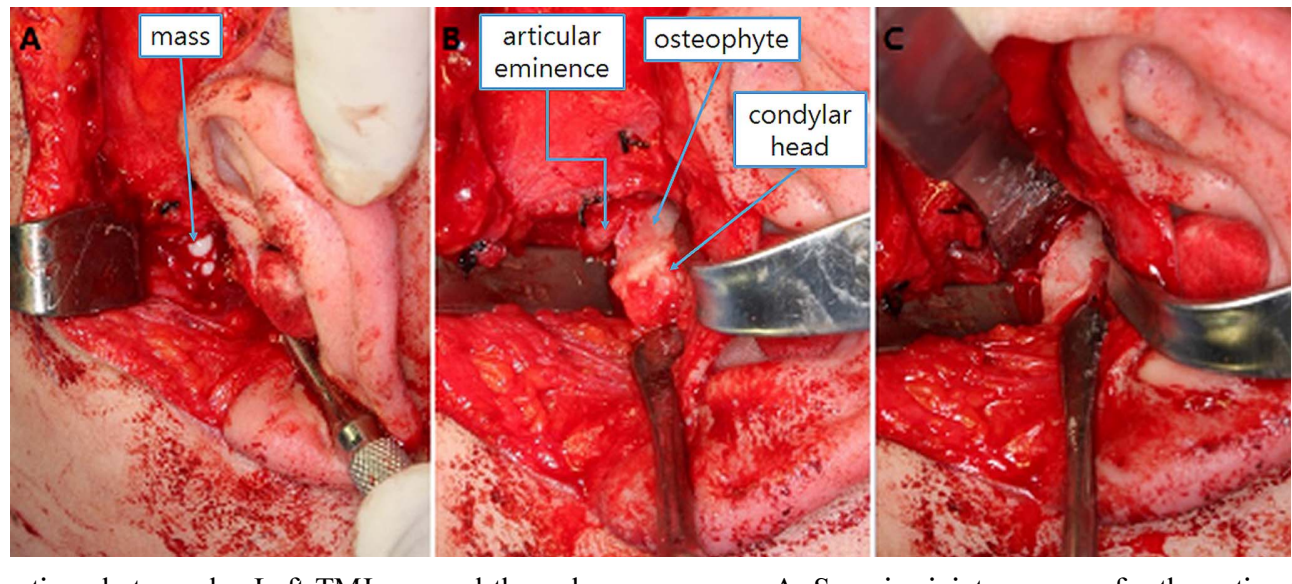

Fig. 2. Intraoperative photographs. Left TMJ exposed through open surgery. A. Superior joint exposure for the extirpation of calcified masses. B. Articular eminence and condyle were exposed. Large osteophyte was observed. Eminectomy was performed. C. Condyle osteophyte was trimmed.

bilateral TMJ was taken under the suspicion of a neoplastic condition. The CBCT examination revealed articular surface bone destruction, left condyle flattening, and glenoid surface remodeling changes on the left TMJ (Fig. 1B, 1C). The superior joint space of the left TMJ was widened. The cranial base at the glenoid fossa was not eroded.

Since relatively less invasive treatments, such as TMJ arthrocentesis, have limitations in resecting numerous calcified masses, open surgery via a preauricular approach was adopted as the therapeutic modality to remove the intra-articular masses that may be the primary cause of the complaint in the patient.

Subsequently, open surgery was performed under general anesthesia. The Alkayat-Bramley flap was modified with a retrotragal modification and the layers were blunt dissected to prevent facial nerve damage. Upon superior joint space exposure, numerous, small hard masses were removed surgically and an eminectomy was performed (Fig. 2A). The lower joint space was also exposed and the impinging condyle osteophytes were trimmed using a vulcanite bur at high speed (Fig. 2B, 2C). Masses were not observed in the inferior joint space. After complete extir- 

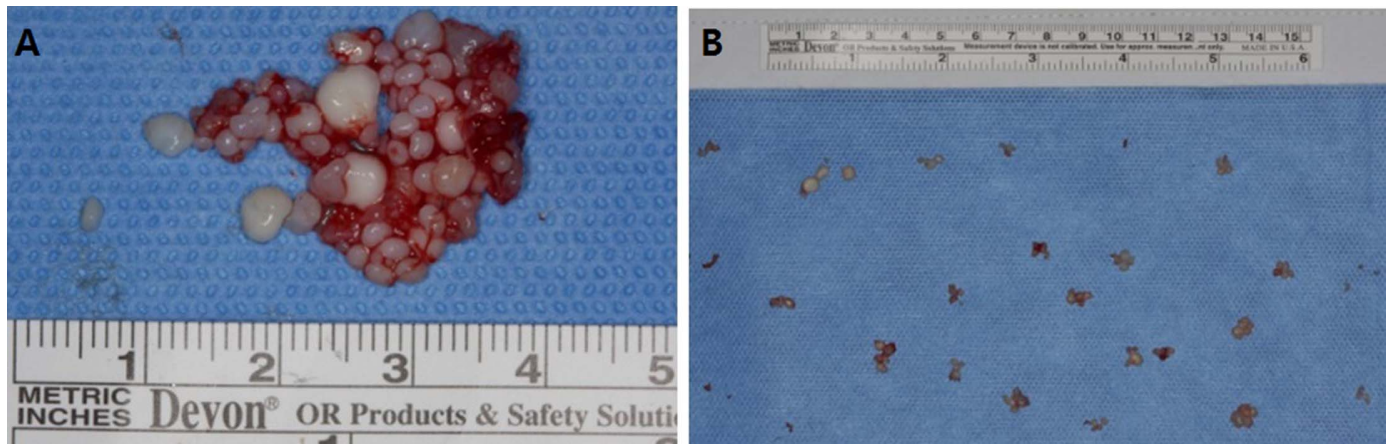

Fig. 3. Panel A and B show a total of 124 calcified masses (SC) that were removed from the superior joint space of the left TMJ.

pation, a silastic drain was inserted in the superior joint space to avoid hematoma and the wound layers were reconstructed.

During open surgery, a total of 124 loose cartilaginous masses and synovial linings were removed (Fig. 3). The resected masses were sent to biopsy for a differential diagnosis. The histopathological examinations of the surgically removed specimen confirmed the presence of numerous fragments of mature cartilaginous tissue, which was consistent with SC.

A day after the surgery, the patient experienced an open bite on the mandibular left posterior region that could be explained by mass removal and condyle osteophyte trimming performed on the left TMJ, as well as transient changes in the articular disc and musculatures on the right TMJ. Intermaxillary fixation screws with attached elastic bands were applied to prevent the development of a malocclusion for 10 days. The silastic drain was removed 3 days after surgery and the sutures were removed after 5 days. The postoperative course was uneventful and the patient was discharged to home 6 days postoperatively after showing good functional recovery without complications.

The patient was followed up routinely, and by three weeks after surgery, diagnostic radiographic examinations were performed. The CT findings showed that there were no residual calcified masses on the left TMJ. At the 6month follow-up, the patient remained symptom free with no apparent signs of recurrence.

\section{Discussion}

Although the pathogenesis and etiology are still unknown, $\mathrm{SC}$ is known to be a benign and chronic disease that usu- ally affects the large synovial joints, such as the elbow and the knee $[5,6]$. Females are more likely to be affected by the disease than males $(2.5: 1)$ and the mean age of patients is approximately 46 years [7-9]. Moreover, the right TMJ joint is affected more than the left $(1.1: 1)$, with only one case of bilateral involvement [9]. When affected by SC, cartilaginous nodules develop within the synovium and they float freely as loose, calcified bodies after being degraded and detached from the joints. In the TMJ, these "loose bodies' are usually limited to the superior joint space and are rarely found in the inferior space [10]. Once calcified, the mass hinders the joint movement and eventually causes swelling, limited mouth opening, crepitation, and other forms of joint dysfunction. In a systematic literature review of 155 cases of SC in the TMJ, the three cardinal signs and symptoms of SC of the TMJ were preauricular pain, swelling, and limited mouth opening [9]. Because calcified masses cause problems, radiological measurements using CT are essential for diagnosing the osseous neoplastic disease of the TMJ [5].

In 1977, Milgram classified SC histopathologically into 3 developmental stages [11]. Yu et al. [12] also divided SC of the TMJ into 3 types radiologically to relate the histopathological and CT findings. According to Yu et al. [12] the CT findings provide useful information in determining Milgram's classification. Within a review of more than hundred cases, large variability existed in the number of loose bodies removed from the TMJ. Only some papers report the exact number and only 3 cases claimed to have removed more than 100 SC nodules: Rootkin-Gray (2003)-110 masses, Sarlani (2004)-109 masses, and Martin-Granizo (2005) over 200 masses [13-15]. In this case, a total of 124 calcified masses were removed from the TMJ.

While open surgery is chosen most widely to extirpate 
calcified nodules, there are reports of smaller SC bodies being removed by arthroscopy [16-18]. Even a large solitary SC of the TMJ can be removed successfully via an additional incision under arthroscopy guidance [19]. Plain $\mathrm{X}$-rays, such as panoramas, often may not detect an abnormality in the joint if cartilaginous bodies are not calcified. In such cases, clinicians could only conjecture by the widening of the joint space and irregular joint surfaces, which are symptoms that may also be manifested in TMD [6]. Therefore, it is important to suspect neoplastic lesions and establish more reliable examinations, such as CT or magnetic resonance imaging (MRI). The patient in the present report was initially misdiagnosed and was given years of failed TMD treatments that did not alleviate her symptoms. The CBCT findings confirmed the patient had SC type 3 (Yu classification), which is defined as detached cartilaginous bodies surrounding the TMJ without soft tissue swelling [12]. Upon a correct diagnosis, the patient underwent open surgery under general anesthesia, and a total of 124 calcified nodules were removed successfully. In addition, recurrence would be highly unlikely as only one case of recurrence has been documented in the literature [20]. This clinical case report describes surgical intervention of TMJ synovial chondromatosis that was initially misdiagnosed as a conventional TMD. The patient's symptoms of pain and discomfort in the joint disappeared after conglomerated calcified nodules were removed from the TMJ.

\section{Conflict of Interest}

The authors declare that they have no competing interests.

\section{ORCID}

Hyun-Suk Kim 0000-0001-7010-4153

Pil-Young Yun 0000-0001-6097-1229

Young-Kyun Kim 0000-0002-7268-3870

\section{References}

1. Auxhausen G. Pathologie und therapie des kiefergelenkes. Fortschr Zahnheilk 1933;9:171.

2. Wu CW, Chen YK, Lin LM, Huang E. Primary synovial chondromatosis of the temporomandibular joint. J Otolaryngol 2004;33:114-119.

3. Vogl TJ, Abolmaali N, Mäurer J, Schedel H, Bergh B. Neoplasms of the temporomandibular joint (TMJ). Diagnosis, differential diagnosis and intervention. Radiologe 2001;41:760-771.

4. Valentini V, Arangio P, Egidi S, Capriotti M, Vellone V, Castrechini M, Boschi G, Cascone P. Diagnosis and treatment of synovial chondromatosis of the TMJ: a clinical case. Ann Stomatol (Roma) 2014;4:269-272.

5. Peyrot H, Montoriol PF, Beziat JL, Barthelemy I. Synovial chondromatosis of the temporomandibular joint: CT and MRI findings. Diagnostic and Interventional Imaging 2014;95: 613-614. doi: 10.1016/j.diii.2013.12.002.

6. Wise DP, Ruskin JD. Arthroscopic diagnosis and treatment of temporomandibular joint synovial chondromatosis: report of a case. J Oral Maxillofac Surg 1994;52:9093. doi: http://dx.doi.org/10.1016/0278-2391(94)90023$\mathrm{X}$.

7. von Lindern JJ, Theuerkauf I, Niederhagen B, Berge S, Appel T, Reich RH. Synovial chondromatosis of the temporomandibular joint: clinical, diagnostic, and histomorphologic findings. Oral Surg Oral Med Oral Pathol Oral Radiol Endod 2002;94:31-38. doi: http://dx.doi.org/ 10.1067/moe.2002.123498.

8. Testaverde L, Perrone A, Caporali L, Ermini A, Izzo L, D'Angeli I, Impara L, Mazza D, Izzo P, Marini M. CT and MR finding in synovial chondromatosis of the temporo-mandibular joint: our experience and review of literature. Eur J Radiol 2011;78:414-418. doi: 10.1016/ j.ejrad.2009.11.015.

9. Guarda-Nardini L, Piccotti F, Ferronato G, Manfredini D. Synovial chondromatosis of the temporomandibular joint: a case description with systematic literature review. Int J Oral Maxillofac Surg 2010;39:745-755. doi: 10.1016/j.ijom. 2010.03.028.

10. Xu WH, Ma XC, Guo CB,Yi B, Bao SD. Synovial chondromatosis of the temporomandibular joint with middle cranial fossa extension. Int J Oral Maxillofac Surg 2007; 36:652655. doi: http://dx.doi.org/10.1016/j.ijom.2007.01.019.

11. Milgram JW. The classification of loose bodies in human joint. Clin Orthop 1977; 124:282-291.

12. Yu Q, Yang J, Wang P, Shi H, Luo J. CT features of synovial chondromatosis in the temporomandibular joint. Oral Surg Oral Med Oral Pathol Oral Radiol Endod 2004;97:524528. doi: http://dx.doi.org/10.1016/j.tripleo.2003.10.027.

13. Sarlani E, Nikitakis NG, Papadimitriou JC, Ord RA. Synchronous occurrence of ipsilateral synovial chondromatosis of the temporomandibular joint and pleomorphic adenoma of the parotid gland. Oral Surg Oral Med Oral Pathol 2004;98:69-75. doi: http://dx.doi.org/10.1016/j.tripleo. 2003.11.005.

14. Rootkin-Gray VF, Fryer L, Robinson PD. 'Mice' in the 
joint. Br J Oral Maxillofac Surg 2003;41:199-200. doi: http://dx.doi.org/10.1016/S0266-4356(03)00066-4.

15. Martin-Granizo R, Sanchez JJ, Jourquera M, Ortega L. Synovial chondromatosis of the temporomandibular joint: a clinical, radiological and histological study. Med Oral Patol Oral Cir Bucal 2005;10:272-276.

16. Pastore GP, Goulart DR, Pastore PR, Prati AJ. Removal of a Solitary Synovial Chondromatosis of the Temporomandibular Joint Using Arthroscopy. J Craniofac Surg 2016;27:967-969. doi: 10.1097/SCS.0000000000002612.

17. Fernández Sanromán J, Costas López A, Antón Badiola I, Fernández Ferro M, López de Sánchez A. Indications of arthroscopy in the treatment of synovial chondromatosis of the temporomandibular joint: report of 5 new cases. J Oral Maxillofac Surg 2008;66:1694-1699. doi: 10.1016/j.joms.2007.09.028.

18. Bai G, Yang C, Qiu Y, Chen M. Open surgery assisted with arthroscopy to treat synovial chondromatosis of the temporomandibular joint. Int J Oral Maxillofac Surg 2017;46:208-213. doi: 10.1016/j.ijom.2016.09.010.

19. Cai XY, Yang C, Chen MJ, Jiang B, Wang BL. Arthroscopically guided removal of large solitary synovial chondromatosis from the temporomandibular joint. Int $\mathrm{J}$ Oral Maxillofac Surg 2010;39:1236-1239. doi: 10.1016/j.jom. 2010.06.013.

20. D'Souza B, Dimitroulis G. A case of recurrence of synovial chondromatosis of the temporomandibular joint. Oral Surg Oral Med Oral Pathol Oral Radiol Endod 2007;104:e59-e61. doi: http://dx.doi.org/10.1016/j.tripleo. 2007.03.026. 